\title{
Fish Oil and Primrose Oil Suppress the Progression of Alzheimer's Like Disease Induced by Aluminum in Rats
}

\author{
Sahar Y. Al-Okbi ${ }^{1 *}$, Shaimaa E Mohammed ${ }^{1}$, Enas S.K. Al-Siedy ${ }^{1}$, and Naglaa A. Ali ${ }^{2}$ \\ ${ }^{1}$ Nutrition and Food Sciences Department, National Research Centre, Cairo, EGYPT \\ ${ }^{2}$ Hormones Department, Medical Research Division, National Research Centre, Cairo, EGYPT
}

\begin{abstract}
The role of fish oil, primrose oil and their mixture in ameliorating the changes in Alzheimer's like model was evaluated in rats. Primrose oil and primrose/fish oil mixture fatty acids composition was assessed by gas chromatography. The rat experiment consisted of 5 groups; the first fed on balanced diet as control normal (CN); the other four groups treated with intraperitoneal aluminum lactate and consumed dyslipidemic diet; one group served as control Alzheimer's like disease (CA) while the other three groups (test groups) received daily oral dose from primrose oil, fish oil and primrose/fish oil mixture separately for 5 weeks. Results showed primrose oil and primrose/ fish oil mixture to contain gamma linolenic acid as 9.15 and $4.3 \%$ of total fatty acids, respectively. Eicosapentaenoic and docosahexaenoic were present as 10.9 and $6.5 \%$, respectively in the oil mixture. Dyslipidemia and increased erythrocyte sedimentation rate (ESR), plasma butyrylcholinesterase (BChE), brain malondialdehyde (MDA) and NO with decrease in plasma magnesium, brain catalase, reduced glutathione, body weight gain and brain weight were demonstrated in CA compared to CN. Brain histopathology and immuno-histochemistry showed neuronal degeneration and neurofibrillary tangles with elevated myeloperoxidase and nuclear factor-kappa B in CA compared to CN. The tested oils demonstrated neuro-protection reflected in the variable significant improvement of biochemical parameters, immuno-histochemistry and brain histopathology. Primrose/fish oil mixture was superior in reducing ESR, brain MDA, plasma activity of $\mathrm{BChE}$ and brain histopathological changes along with elevating plasma magnesium. Primrose/fish oil mixture and fish oil were more promising in improving plasma high density lipoprotein cholesterol (HDL-C) than primrose. Fish oil was the most efficient in improving plasma total cholesterol (T-C), low density lipoprotein cholesterol and T-C /HDL-C. Primrose/ fish oil mixture and primrose oil were superior in elevating brain catalase compared to fish oil. Other parameters were equally improved by the different oil treatments. Primrose oil, fish oil and their mixture reduced the progression of Alzheimer's disease in rats with superiority to primrose/fish oil mixture.
\end{abstract}

Key words: fish oil, primrose oil, Alzheimer's disease, rats, aluminum

\section{Introduction}

Aluminum $(\mathrm{Al})$ is a neurotoxic element implicated in the pathology and progression of Alzheimer's disease (AD). Al deposits in the brain and neurons lead to high oxidative stress and apoptosis of neurons with alteration of bloodbrain barrier ${ }^{1,2)}$. Treatment with aluminum salts induces a significant impairment in memory and learning ability in animals $^{3)}$. $\mathrm{Al}$ is a cholinotoxin element producing neuronal loss by altering nicotinic receptors ${ }^{4}$; therefore, $\mathrm{Al}$ induces Alzheimer's like changes. Unfortunately, $\mathrm{Al}$ enters in many industries including drugs and home utensils leading to high exposure to human. Alzheimer's disease is a neurodegenerative disorder and the most common form of dementia characterized by a progressive cognitive impairment and memory loss due to neuronal degeneration, elevated acetylcholinesterase, deposition of neurofibrillary tangles and beta amyloid $(A \beta)$ plaque which contains $A \beta$ peptides. Inflammation and oxidative stress are among the main features of $\mathrm{AD}^{5)}$. Myeloperoxidase produced an array of oxidants that induced tissue damage during inflammation and the further expression of such enzyme contributes to the pathological changes in the brains of $\mathrm{AD}$ patients ${ }^{6}$. Nuclear

\footnotetext{
*Correspondence to: Sahar Y. Al-Okbi, Nutrition and Food Sciences Department, National Research Centre, Cairo, EGYPT

E-mail: S_Y_alokbi@hotmail.com

Accepted March 9, 2020 (received for review February 16, 2020)

Journal of Oleo Science ISSN 1345-8957 print / ISSN 1347-3352 online

http://www.jstage.jst.go.jp/browse/jos/ http://mc.manusriptcentral.com/jjocs
} 
factor-Kappa $\mathrm{B}(\mathrm{NF}-\mathrm{\kappa B})$ is a protein complex that control transcription of DNA, cytokine production and cell survival and it is a key regulator of innate immunity, NF- $\mathrm{kB}$ was recently reported as a possible risk factor in $\mathrm{AD}$ model and that it must be targeted for disease prevention ${ }^{7}$. Vascular diseases and dyslipidemia were accused for enhancing the onset and progression of $\mathrm{AD}^{8)}$. The role of $\mathrm{Al}$ and dyslipidemia in induction of $\mathrm{AD}$ was exploited to establish an animal model for Alzheimer's like disease ${ }^{9)}$ to study the efficacy of new therapies and dietary supplements.

So far, no efficacious therapy is present for $\mathrm{AD}$ except for just alleviation of the symptoms. The elevated incidence of $\mathrm{AD}$ owing to increased number of elderly necessitates a real dietary strategy and search for remedy. Omega-3 fatty acids (n-3) like eicosapentaenoic (EPA) and docosahexaenoic (DHA) are important for neurons and immune function. They possess antiinflammatory and blood anticoagulant effect and proposed to preserve cognitive function ${ }^{10)}$. Omega-3 polyunsaturated fatty acids were reported to promote brain to blood clearance of $\beta$-amyloid in $\mathrm{AD}$ model in mice ${ }^{11)}$. Gamma-linolenic fatty acids in evening primrose oil (EPO) are precursor of the anti-inflammatory eicosanoids and possess antioxidant activity ${ }^{12,13)}$ that might prevent neurodegeneration.

The aim of the present research was to study the beneficial effect of fish oil, primrose oil and their mixture in rat model of Alzheimer's like disease induced by intraperitoneal aluminum lactate and enhanced by feeding dyslipidemic diet. Biochemical parameters reflecting oxidative stress and inflammation were studied in the brain. In addition, plasma lipid profile, magnesium and butyrylcholine esterase were determined together with brain histopathology and immuno-histochemistry for myeloperoxidase and $\mathrm{NF}-\kappa \mathrm{B}$. The fatty acid composition of EPO and primrose/ fish oil mixture was studied.

\section{Experimental}

\subsection{Materials}

Evening primrose oil (Oenothera biennis L. Family: Onagraceae) was obtained from the pharmacy, Egypt under the commercial name primaleve capsules (GalaxoSmithkline pharmaceutical and health care Company). Fish oil capsules (source: anchovy, mackerel, sardine and tuna) were purchased from iHerb (Hebron, KY), United States.

\subsection{Chemicals}

Aluminum lactate was purchased from Riedel-de Haën, Seelze, Germany for induction of Alzheimer's like disease model in rats.

\subsection{Animals}

Male albino rats of body weight ranging from 140 to 160 g were obtained from Research Institute of Ophthalmology, Giza, Egypt. Animals were kept individually in stainless steel cages. Water and food were given ad-libtium with 12 $\mathrm{h}$ light/dark cycle. The animals received humane care according to the Medical Research Ethics Committee, National Research Centre, Cairo, Egypt, and the study followed the recommendations of the National Institutes of Health Guide for Care and Use of Laboratory Animals (Publication No. 85-23, revised 1985); registration No. 18205.

\subsection{Methods}

2.4.1 Determination of fatty acids profile in primrose and primrose/fish oil mixture by gas chromatography (GC)

Methanol sulphuric acid and chloroform mixture was used for preparation of fatty acids methyl esters ${ }^{14)}$. Hewlett Packard HP-system 6890 GC equipped with flame ionization detector. HP-5 column $(30 \mathrm{~m} \times 0.32 \mathrm{~mm}$ i.d.; $0.25 \mu \mathrm{m}$ film thickness) was used for separation of fatty acids methyl esters. The conditions of GC were; $70^{\circ} \mathrm{C}$ as an initial temperature that hold for $1 \mathrm{~min}$ then elevated to $120^{\circ} \mathrm{C}$ with a rate of $40^{\circ} \mathrm{C} / \mathrm{min}$, then 2 min hold and the temperature was finally raised to $220^{\circ} \mathrm{C}$ with a rate of $4^{\circ} \mathrm{C} / \mathrm{min}$ with another 20 min hold. The temperature of detector and injector were 280 and $250^{\circ} \mathrm{C}$, respectively. Fatty acids methyl esters were identified by direct comparison of their retention times with that of standards analyzed at the same conditions. Quantization was based on peak area integration. Supelco standard fatty acid methyl esters obtained from Merck, Darmstadt, Germany was used.

\subsubsection{Preparation of diets}

Two diets were prepared as shown in Table 1. A balanced diet was prepared according to previous research ${ }^{15}$. The dyslipidemic diet contained sucrose, sheep tallow, cholesterol and bile salts while devoid of cellulose. The composition of the dyslipidemic diet was similar to that prepared previously ${ }^{16,17}$ with minor modifications.

2.4.3 Preparation of dosage form of the oils.

Fish oil was mixed with primrose oils $(1: 1$, w/w $)$ to prepare the oil mixture. To facilitate dosing of different oils to rats; they were prepared into emulsion form. Fish oil, primrose oil and primrose/fish oil mixture were added separately to tween 80 (10\% of oil weight) mixed well with vortex with drop-wise addition of water to prepare three oil in water emulsions. It was taken into consideration to use fixed quantities of tween and water in each emulsion. A vehicle was made by mixing tween 80 and water with the same ratio as in the oil emulsions (for dosing to control groups of rats). The dose was $270 \mathrm{mg}$ from each oil/kg rat body weight according to previous study ${ }^{13)}$.

2.4.4 Design of animal experiment to evaluate the efficacy of different oils towards Alzheimer's like disease

To induce Alzheimer's like disease in rats; Al lactate was dissolved in saline to be given intra-peritoneal to rats as 7.5 
Table 1 Composition of different experimental diets $(\mathrm{g} / 100 \mathrm{~g})$.

\begin{tabular}{|c|c|c|}
\hline Ingredients & Balanced diet & $\begin{array}{c}\text { Dyslipidemic } \\
\text { diet }\end{array}$ \\
\hline Casein & 12.00 & 12.00 \\
\hline Sheep tallow & - & 20.00 \\
\hline Sun flower oil & 10.00 & - \\
\hline Maize starch & 68.50 & 20.70 \\
\hline Sucrose & - & 41.55 \\
\hline Cellulose & 5.00 & - \\
\hline Salt mixture & 3.50 & 3.50 \\
\hline Vitamin Mixture & 1.00 & 1.00 \\
\hline Cholesterol & - & 1.00 \\
\hline Bile salt & - & 0.25 \\
\hline Total & 100 & 100 \\
\hline
\end{tabular}

mg Al/kg rat body weight/day (only 4 days per week) for 5 weeks. Induction of Alzheimer's was enhanced by feeding dyslipidemic diet to rats during treatment with $\mathrm{Al}$. This adopted procedure is similar to previous works ${ }^{5,9)}$.

The rats were divided into 5 groups; each of eight rats. Rats of four groups were treated with intraperitoneal aluminum lactate as $7.5 \mathrm{mg} \mathrm{Al} / \mathrm{Kg}$ rat body weight (4 days a week) and fed on hyperlipidemic diet; one group served as control Alzheimer's like disease (CA) while the other three groups (test groups) received daily oral dose $(270 \mathrm{mg} / \mathrm{Kg}$ rat body weight) of primrose oil, fish oil and primrose/fish oil mixture separately. The rats of the fifth group were fed on balanced diet as control normal $(\mathrm{CN})$. Rats of $\mathrm{CA}$ and $\mathrm{CN}$ groups received daily oral dose of the vehicle. Rats of CN group were treated by intra-peritoneal saline (4 days/ week). The experiment continued for 5 weeks. During the experiment; body weight and food intake were recorded weekly. At the end of the experiment body weight gain and total food intake were calculated. Blood samples were drawn from fasted anaesthetized rats and divided into two parts, one mixed with trisodium citrate for determination of erythrocyte sedimentation rate $(\mathrm{ESR})^{18}$ while the second part was received in heparinized tubes and centrifuged at $3000 \mathrm{rpm}(0.235 \mathrm{~g})$ for $15 \mathrm{~min}$ for separation of plasma. Plasma total cholesterol (T-C), triglycerides (TG) and high density lipoprotein cholesterol(HDL-C) were determined by colorimetric technique ${ }^{19-21)}$ while LDL-C was calculated ${ }^{22)}$. Plasma butyrylcholinesterase (BChE) activity was estimated adopting colorimetric kinetic method ${ }^{23)}$. Plasma magne$\operatorname{sium}(\mathrm{Mg})$ was assessed according to previous colorimetric procedure $^{24)}$. Brain was immediately received on ice and cut into two longitudinal sections; a part was used for assessment of nitrite $(\mathrm{NO})^{25)}$, malondialdehyde $(\mathrm{MDA})^{26)}$,

Table 2 Fatty acids composition of primrose oil and primrose /fish oil mixture as percentage of total fatty acids.

\begin{tabular}{lcc}
\hline \multicolumn{1}{c}{ Fatty acids } & Primrose oil & $\begin{array}{c}\text { Primrose /Fish } \\
\text { oil mixture }\end{array}$ \\
\hline Myristic acid, C14:0 & - & 3.60 \\
Palmitic, C16:0 & 6.80 & 12.30 \\
Palmitoleic, C16:1 & - & 4.80 \\
Stearic, C18:0 & 2.36 & 3.50 \\
Oleic, C18:1 & 9.17 & 10.50 \\
Linoleic, C18:2 (n-6) & 67.74 & 34.40 \\
Gamma linolenic C18: 3 (n-6) & 9.15 & 4.30 \\
Q-linolenic C18:3 (n-3) & - & 1.40 \\
Arashidic, C20:0 & 0.49 & 0.21 \\
EPA, C20:5 (n-3) & - & 10.90 \\
DHA, C22: 6 (n-3) & - & 6.50 \\
Total saturated fatty acids & $\mathbf{9 . 6 5}$ & $\mathbf{1 9 . 6 1}$ \\
Total unsaturated fatty acids & $\mathbf{8 6 . 0 6}$ & $\mathbf{7 2 . 8 0}$ \\
Total monounsaturated fatty acids & $\mathbf{9 . 1 7}$ & $\mathbf{1 5 . 3 0}$ \\
n-6/n-3 & $\mathbf{7 6 . 8 9 : 0 *}$ & $\mathbf{2 . 0 6 : 1}$ \\
\hline
\end{tabular}

*: n-3 fatty acids were not detected in primrose i.e. equal 0.

$\mathrm{n}-6=\omega 6$

$\mathrm{n}-3=\omega 3$ 
S. Y. Al-Okbi, S. E Mohammed, E. S.K. Al-Siedy et al.

Table 3 ESR and plasma lipid profile, BChE and Mg and brain MDA, CAT, GSH and NO of different experimental groups $($ Mean $\pm \mathrm{SE})$.

\begin{tabular}{|c|c|c|c|c|c|}
\hline Parameters $\quad$ Groups & $\mathrm{CN}$ & $\mathrm{CA}$ & Primrose oil & Fish oil & $\begin{array}{l}\text { Primrose/ fish oil } \\
\text { mixture }\end{array}$ \\
\hline ESR & $2.06^{\mathrm{a}} \pm 0.07$ & $18.01^{\mathrm{d}} \pm 0.3$ & $11.47^{\mathrm{bc}} \pm 0.28$ & $12.29^{\mathrm{c}} \pm 0.4$ & $11.17^{\mathrm{b}} \pm 0.26$ \\
\hline \multicolumn{6}{|l|}{ Plasma parameters: } \\
\hline $\mathrm{TG}(\mathrm{mg} / \mathrm{dl})$ & $81.2^{\mathrm{a}} \pm 1.1$ & $112.2^{\mathrm{c}} \pm 0.6$ & $102.7^{\mathrm{b}} \pm 0.6$ & $104.8^{\mathrm{b}} \pm 0.4$ & $104.5^{\mathrm{b}} \pm 0.9$ \\
\hline $\mathrm{T}-\mathrm{C}(\mathrm{mg} / \mathrm{dl})$ & $89.2^{\mathrm{a}} \pm 0.6$ & $149.2^{\mathrm{e}} \pm 0.5$ & $108.1^{\mathrm{d}} \pm 0.5$ & $91.7^{\mathrm{b}} \pm 0.6$ & $102.1^{\mathrm{c}} \pm 1.1$ \\
\hline HDL-C (mg/dl) & $48.1^{\mathrm{d}} \pm 0.3$ & $30.3^{\mathrm{a}} \pm 0.8$ & $34.8^{\mathrm{b}} \pm 0.4$ & $36.1^{\mathrm{bc}} \pm 0.4$ & $37.1^{c} \pm 0.3$ \\
\hline LDL-C (mg/dl) & $24.9^{\mathrm{a}} \pm 0.7$ & $96.5^{\mathrm{e}} \pm 1.1$ & $52.7^{\mathrm{d}} \pm 0.9$ & $34.7^{\mathrm{b}} \pm 0.8$ & $44.2^{c} \pm 1.1$ \\
\hline T-C/HDL-C & $1.9^{\mathrm{a}} \pm 0.02$ & $4.9^{\mathrm{e}} \pm 0.10$ & $3.1^{\mathrm{d}} \pm 0.10$ & $2.5^{\mathrm{b}} \pm 0.04$ & $2.8^{\mathrm{c}} \pm 0.04$ \\
\hline $\mathrm{BChE} \mathrm{U/L}$ & $170^{\mathrm{a}} \pm 0.71$ & $220^{\mathrm{e}} \pm 0.70$ & $191^{\mathrm{c}} \pm 0.87$ & $201^{\mathrm{d}} \pm 0.96$ & $177.8^{\mathrm{b}} \pm 1.00$ \\
\hline $\operatorname{Mg}(\mathrm{mg} / \mathrm{dl})$ & $2.6^{\mathrm{b}} \pm 0.03$ & $2.13^{\mathrm{a}} \pm 0.05$ & $2.19^{\mathrm{a}} \pm 0.06$ & $2.18^{\mathrm{a}} \pm 0.06$ & $2.5^{\mathrm{b}} \pm 0.03$ \\
\hline \multicolumn{6}{|l|}{ Brain parameters: } \\
\hline MDA(nmol/g tissue) & $93.30^{\mathrm{d}} \pm 1.30$ & $165.29^{\mathrm{e}} \pm 1.20$ & $87.89^{c} \pm 1.25$ & $83.31^{b} \pm 1.00$ & $79.67^{\mathrm{a}} \pm 0.67$ \\
\hline CAT U/g.tissue & $0.43^{\mathrm{d}} \pm 0.03$ & $0.07^{\mathrm{a}} \pm 0.02$ & $0.23^{\mathrm{c}} \pm 0.01$ & $0.15^{b} \pm 0.03$ & $0.24^{c} \pm 0.03$ \\
\hline GSH mmol/g.tissue & $77.13^{\mathrm{b}} \pm 5.02$ & $32.75^{\mathrm{a}} \pm 3.03$ & $63.88^{\mathrm{b}} \pm 6.28$ & $65.75^{\mathrm{b}} \pm 6.62$ & $72.25^{\mathrm{b}} \pm 1.92$ \\
\hline $\mathrm{NO} \mu \mathrm{mol} / \mathrm{g}$.tissue & $0.95^{\mathrm{b}} \pm 0.006$ & $1.25^{\mathrm{c}} \pm 0.004$ & $0.88^{\mathrm{ab}} \pm 0.034$ & $0.88^{\mathrm{ab}} \pm 0.163$ & $0.85^{\mathrm{a}} \pm 0.356$ \\
\hline
\end{tabular}

In the same row; different superscript letters mean significant difference at $p<0.05$ while similar superscript letters mean insignificant change.

No. of rats in each group: 8

CN: Control normal, CA: Control Alzheimer's like disease, ESR: Erythrocyte sedimentation rate, TG: Triglycerides, T-C: Total cholesterol, HDL-C: High density lipoprotein cholesterol, LDL-C: Low density lipoprotein cholesterol, BChE: Butyryl cholinesterase, MDA: Malondialdehyde, CAT: Catalase, GSH: Reduced glutathione, NO: Nitric oxide.

reduced glutathione $(\mathrm{GSH})^{27}$ and catalase activity ${ }^{28}$ while the other part was fixed in 10\% formalin for application of immuno-histochemistry for myeloperoxidase and NF- $\mathrm{KB}^{29)}$ and histopathological examination ${ }^{30)}$.

2.3.5 Statistical analysis

The results of animal experiment were expressed as the Mean \pm SE and they were analyzed statistically using the one-way analysis of variance ANOVA followed by Tukey test. In all cases $p<0.05$ was used as the criterion of statistical significance.

\section{Results}

\subsection{Fatty acids profile in primrose and primrose/fish oil mixture}

The fatty acids composition of primrose and primrose/ fish oil mixture is shown in Table 2. It could be noticed that the major fatty acid in both primrose oil and the oil mixture was the $\omega 6$ linoleic (67.74 and $34.40 \%$, respectively) that showed double the percentage in primrose oil compared to the oil mixture. Gamma-linolenic in primrose constituted more than twice the percentage in the oil mixture $((9.15 \%$ and $4.30 \%$, respectively). Oleic acid showed slightly lower percentage in primrose oil $(9.17 \%)$ compared to that in the oil mixture $(10.50 \%)$. Total saturated fatty acids reached $9.65 \%$ and 19.61 in primrose oil and the oil mixture, respectively which showed very lower percentage in case of primrose oil compared to the oil mixture. Total unsaturated fatty acids were $86.06 \%$ and monounsaturated fatty acids were $9.17 \%$ in primrose while they were 72.80 and 15.30 in the oil mixture; which reflects appreciably higher percentage of total unsaturated fatty acids and lower percentage of monounsaturated fatty acids in primrose compared to the oil mixture. It was observed that n-6: n-3 was 76.89: 0 and 2.06: 1 in primrose and the oil mixture, respectively.

\subsection{Results of animal experiment}

ESR, plasma TG, T-C, LDL-C, T-C/HDL-C and BChE of CA group showed significant increase compared to that of $\mathrm{CN}$ (Table 3). There were significant reduction of plasma HDL-C and Mg levels of CA group compared to CN group. Treatment with the different oils showed significant reduction of ESR, plasma TG, T-C, LDL-C, T-C/HDL-C and BChE with significant increase in HDL-C compared to CA. Only administration of the oil mixture from the test groups showed significant increase in plasma Mg compared to CA. ESR and all plasma parameters levels of the test groups could not reach the normal levels of the $\mathrm{CN}$ group. Plasma $\mathrm{Mg}$ level of the group that was given the oil mixture 
Fish and Primrose Oils Suppress Alzheimer's Disease Progression

Table 4 Nutritional parameters and brain weight of different experimental groups (Mean $\pm \mathrm{SE}$ ).

\begin{tabular}{lccccc}
\hline Proups & $\begin{array}{c}\text { Initial body } \\
\text { weight }(\mathrm{g})\end{array}$ & $\begin{array}{c}\text { Final body } \\
\text { weight }(\mathrm{g})\end{array}$ & $\begin{array}{c}\text { Body weight } \\
\text { gain }(\mathrm{g})\end{array}$ & $\begin{array}{c}\text { Total food intake } \\
(\mathrm{g})\end{array}$ & Brain weight $(\mathrm{g})$ \\
\hline $\mathrm{CN}$ & $153.00^{\mathrm{a}} \pm 5.41$ & $217.33^{\mathrm{c}} \pm 4.53$ & $64.33^{\mathrm{c}} \pm 8.23$ & $405.00^{\mathrm{c}} \pm 5.16$ & $1.60^{\mathrm{c}} \pm 0.03$ \\
CA & $152.14^{\mathrm{a}} \pm 3.43$ & $163.71^{\mathrm{a}} \pm 4.30$ & $11.57^{\mathrm{a}} \pm 3.74$ & $143.29^{\mathrm{a}} \pm 13.27$ & $1.42^{\mathrm{a}} \pm 0.01$ \\
Primrose oil & $152.00^{\mathrm{a}} \pm 4.90$ & $188.44^{\mathrm{b}} \pm 4.82$ & $36.44^{\mathrm{b}} \pm 3.1$ & $221.11^{\mathrm{b}} \pm 8.07$ & $1.52^{\mathrm{b}} \pm 0.02$ \\
Fish oil & $152.70^{\mathrm{a}} \pm 2.32$ & $195.43^{\mathrm{b}} \pm 5.75$ & $42.71^{\mathrm{b}} \pm 5.49$ & $215.29^{\mathrm{b}} \pm 18.45$ & $1.58^{\mathrm{bc}} \pm 0.03$ \\
Oil mixture & $152.60^{\mathrm{a}} \pm 2.80$ & $203.90^{\mathrm{bc}} \pm 5.59$ & $51.30^{\mathrm{bc}} \pm 5.55$ & $214.50^{\mathrm{b}} \pm 11.01$ & $1.59^{\mathrm{bc}} \pm 0.02$ \\
\hline
\end{tabular}

In the same column; different superscript letters mean significant difference at $p<0.05$ while similar superscript letters mean insignificant change.

No. of rats in each group: 8

CN: Control normal, CA: Control Alzheimer's s like disease.

Table 5 Effect of severity of histopathological alterations in the brain of different experimental groups.

\begin{tabular}{|c|c|c|c|c|c|}
\hline $\begin{array}{l}\text { Histopathological Changes } \\
\text { in hippocampus and cerebral cortex }\end{array}$ & $\mathrm{CN}$ & $\mathrm{CA}$ & Primrose oil & Fish oil & $\begin{array}{c}\text { Primrose/fish } \\
\text { oil mixture }\end{array}$ \\
\hline Degeneration of neurons & - & +++ & +++ & ++ & ++ \\
\hline Necrosis of neurons & - & +++ & ++ & + & + \\
\hline neurofibrillary tangles & - & +++ & +++ & ++ & ++ \\
\hline Perivascular edema & - & ++ & - & + & - \\
\hline Focal hemorrhages & - & ++ & + & - & - \\
\hline
\end{tabular}

CN: Control normal, CA: Control Alzheimer's like disease

+++ Severe, ++ moderate, + mild, - Nil.

showed insignificant change from $\mathrm{CN}$.

Brain tissue demonstrated significant increase in MDA and NO along with significant reduction of CAT and GSH in CA group compared to CN group (Table 3). Treatment with the different oils reduced MDA and NO significantly compared to CA. The levels of MDA of the test groups showed significant reduction compared to CN. Administration of either primrose or fish oil produced insignificant change in NO while the oil mixture showed significant reduction compared to $\mathrm{CN}$. The test groups produced significant increase in both CAT and GSH compared to CA. Brain CAT activity showed significant reduction while GSH demonstrated insignificant change compared to $\mathrm{CN}$.

Nutritional parameters and brain weights are compiled in Table 4. Final body weight, body weight gain, food intake and brain weight of CA group showed significant reduction compared to CN. Treatment with the tested oils produced significant increase in final body weight, body weight gain, food intake and brain weight compared to CA group. Final body weight and body weight gain of the group given the oil mixture showed insignificant change from CN while administration of either primrose or fish oil still showed significant reduction of such parameters from CN. Total food intake of the test groups demonstrated significant reduc- tion compared to $\mathrm{CN}$ group. Brain weights of rats of the groups given primrose oil showed significant reduction compared to CN. Treatment with either fish oil or the oil mixture produced insignificant change of brain weights compared to $\mathrm{CN}$.

\subsection{Brain histopathological changes}

Histopathological changes of the brain are present in Fig. 1 and Table 5. It could be seen that brain of CA group showed degeneration and pyknosis in neurons with formation of focal amorphous eosinophilic materials in the cerebral cortex (Fig. 1A). Brain of the same group demonstrated necrosis of the neurons and formation of focal area of malacia at the cerebral cortex, neuritic plaques and neurofibrillary tangles (Fig. 1B). It could be also noticed from Fig. $1 \mathrm{C}$ that brain of CA group showed neurofibrillary tangles in different areas of the brain with abnormal distribution of neurons, fibrotic changes and neuritic threads. CA group illustrated severe formation of neurofibrillary tangles in hippocampus together of focal area of hemorrhages and gliosis in the brain tissue (Figs. 1D and E). Normal control group showed normal appearance of brain cells and neurons (Fig. 1F). The three test groups treated with primrose oil, fish oil and the oil mixture demonstrated 


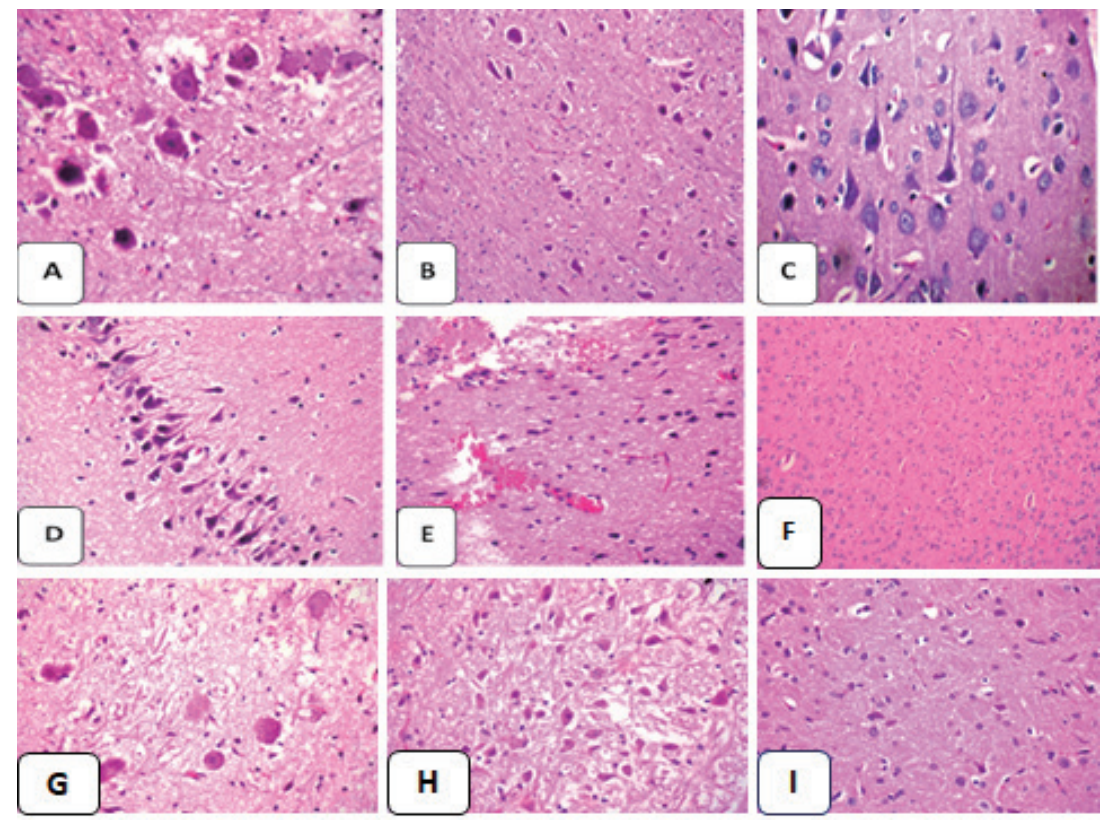

Fig. 1 Brain sections (stained by hematoxylin and eosin) of rats treated by aluminum lactate and served as control Alzheimer's like disease (A-E), normal control group (F), group treated by fish oil (G), primrose (H) and oil mixture (I). A: The photomicrograph of brain section (magnification $\times 200$ ) illustrated degeneration and pyknosis in neurons with formation of focal amorphous eosinophilic materials in the cerebral cortex. B: Photomicrograph of brain section (magnification $\times 100)$ showed necrosis of the neurons and formation of focal area of malacia at the cerebral cortex, neuritic plaques and neurofibrillary tangles. C: Photomicrograph of brain section (magnification X400) demonstrated neurofibrillary tangles in different areas of the brain with abnormal distribution of neurons, fibrotic changes and neuritic threads. D: Photomicrograph of brain section (magnification $\times 400$ ) illustrated severe formation of neurofibrillary tangles in hippocampus. E: Photomicrograph of brain section (magnification $\times 400)$ showed focal area of hemorrhages and gliosis in the brain tissue. F: Photomicrograph of brain (magnification X200) showed normal appearance of brain cells and neurons. G: Photomicrograph of brain (magnification X400) illustrated mild to moderate degenerative changes of neurons. $\mathrm{H}$ : Photomicrograph of brain (magnification $\times 400$ ) demonstrated moderate degeneration and necrosis of neurons. I: Photomicrograph of brain (magnification X400) illustrated mild degenerative changes of neurons.

improvement in brain histopathological changes where administration of the oil mixture showed superiority followed by fish oil, then primrose oil (Figs. 1G, H, I and Table 5).

\subsection{Immuno-histochemistry for brain NF- $\kappa B$ and myelo- peroxidase}

Figures 2B and 3B illustrate that CA group showed severe reaction concerning both $\mathrm{NF}-\kappa \mathrm{B}$ and myeloperoxidase in the brain while administration of primrose oil, fish oil and the oil mixture reduced the level of both NF- $\kappa B$ and myeloperoxidase to moderate (Figs. 2C, D, E and Figs. 3C, $\mathrm{D}, \mathrm{E})$.

\section{Discussion}

The pathophysiology of $\mathrm{AD}$ is a complicated pathway which is not well understood. High oxidative stress in the brain represented by elevated MDA, NO and reduced GSH and enzymatic antioxidants might be one arm of $\mathrm{AD}$ pathogenesis $^{5)}$. Such high oxidative stress could enhance brain neuro-inflammation which consequently might lead to necrosis and apoptosis of brain cells. On the other hand, the deposition of $\mathrm{A} \beta$ and neurofibrillary tangles in the brain was reported as being main features of $\mathrm{AD}$ that might initiate free radicals and inflammation ${ }^{31)}$. Recently high expression of myeloperoxidase was reported in $\mathrm{AD}$ which participates in the induction of oxidative stress that could certainly lead to necrosis and apoptosis of brain cells ${ }^{6)}$. $\mathrm{NF}-\kappa \mathrm{B}$ was highly expressed in AD leading to increased release of inflammatory cytokines that prime inflammation in the brain of $\mathrm{AD}$ patients with simultaneous transcription of DNA that potentiates cell disintegration and death in the brain $^{7)}$. Elevated acetylcholine esterase and BChE play an important role in pathogenesis of $\mathrm{AD}$ due to reducing acetylcholine transmitter which is very essential for memory $^{32)}$. The increase in plasma BChE was seen in the $\mathrm{AD}$ like model in the present study with elevation of brain 


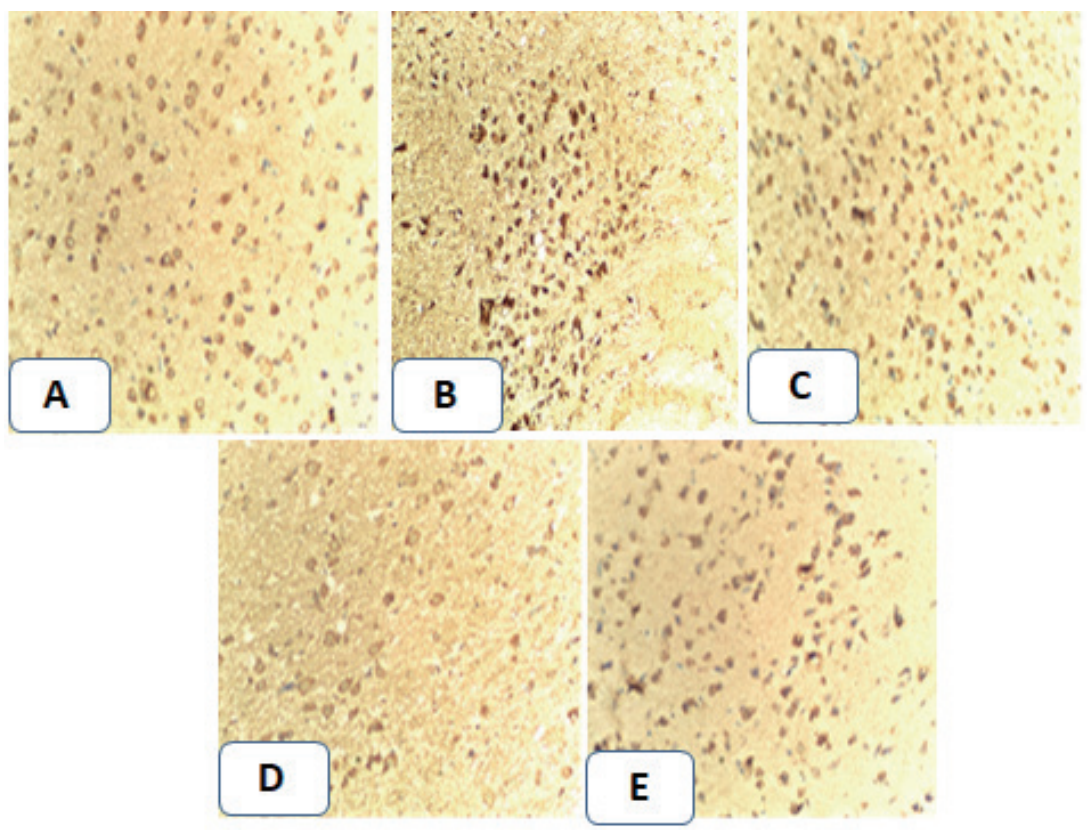

Fig. 2 Photograph for NF-kB immuno-histochemical staining of brain tissue section of rats (X200): A: Control normal group showed mild reaction of NF-кB immunopositive cells. B: The group treated by aluminum lactate and served as control Alzheimer's like disease illustrated severe increase in reaction of NF-кB. C: Group treated with fish oil

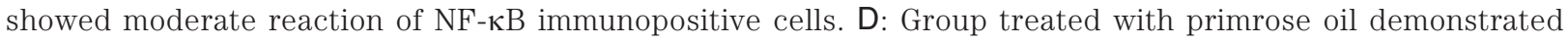
moderate positive reaction in NF-kB immunopositive cells. E: Group treated with oil mixture showed moderate positive reaction in NF-אB immunopositive cells.

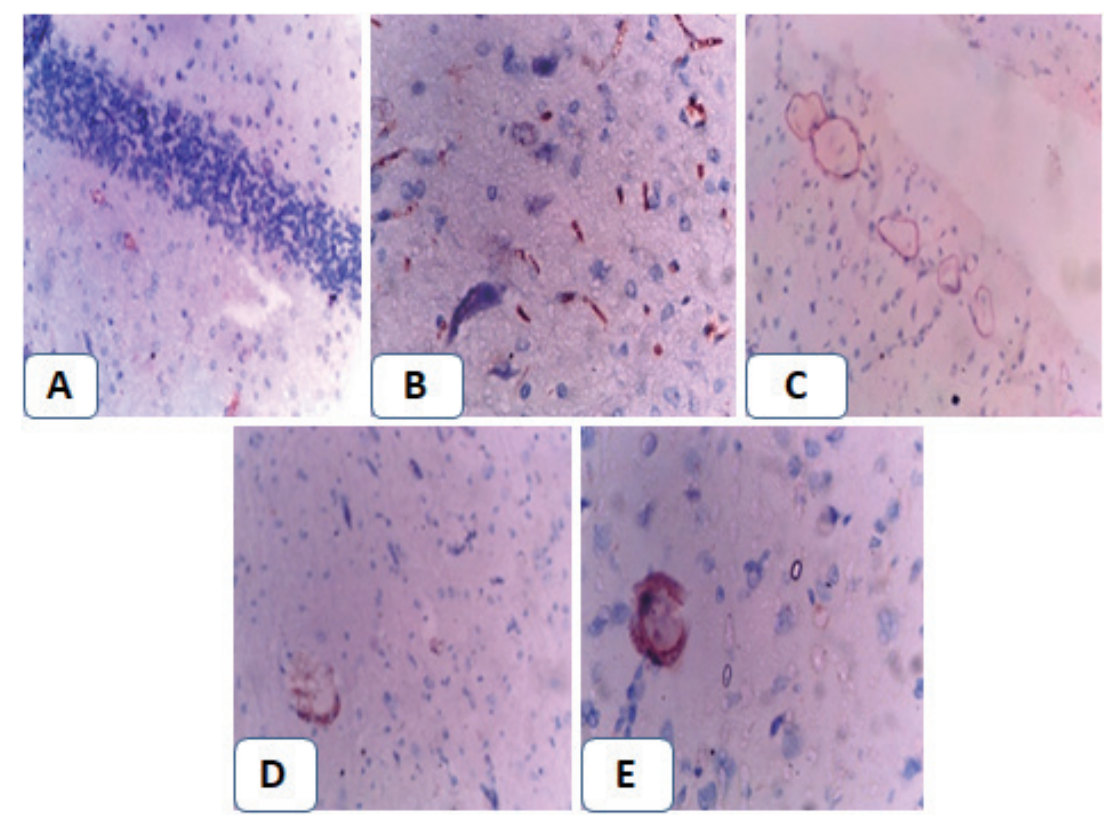

Fig. 3: Photograph for myeloperoxidase immunohistochemical staining of brain tissue section of rats (X200). A: negative control group showed mild positive reaction in myloperoxidase immunopositive cells. B: The group treated by aluminum lactate and served as control Alzheimer's like disease illustrated severe increase(highly positive) in myeloperoxidase immune-positive cells. C: Group treated with fish oil demonstrated moderate positive reaction in myeloperoxidase immune-positive cells. D: Group treated with primrose oil showed moderate positive reaction in myeloperoxidase immune-positive cells. E: Group treated with oil mixture demonstrated moderate positive reaction in myeloperoxidase immune-positive cells. 
oxidative stress and inflammation represented by increased MDA, NO and ESR and reduced GSH and catalase with in-

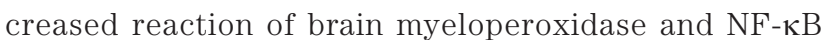
which pointed to changes simulating that of $\mathrm{AD}$ in human. Also, plasma $\mathrm{Mg}$ was reduced in the $\mathrm{AD}$ model in the present study. Reduced levels of Mg were reported in serum and various tissues of AD patients and negatively correlated with disease deterioration through modulation of the processing of amyloid beta precursor protein. $\mathrm{Mg}$ deficiency lead to impairment in emotional memory while $\mathrm{Mg}$ therapy recover cognitive function since it enhances short and long-term synaptic function and improves learning and memory in rats but within certain limits of dose level ${ }^{33,34)}$. Brain histopathological changes represented by cell necrosis, hemorrhage, disintegration, necrosis, malacia and neurofibrillary tangles mostly in cerebral cortex and hippocampus further confirmed the induction of $\mathrm{AD}$ like model in the current study. Pyknosis was also noticed in brain sections which is the irreversible precipitation of chromatin in cell nucleus that undergoing necrosis or apoptosis this means that the followed step is karyorrhexis or fragmentation of the nucleus of brain cell. Damage in central nervous system produced nonspecific reactive change in glial cells known as gliosis which was seen in the brain cell in the present study. Gliosis involves hypertrophy of glial cells represented by astrocytes, microglia and oligodendrocytes. Also, neurotic plaques (Senile plaques) were observed in brain histopathology of $\mathrm{AD}$ rats in the current work. These neurotic plaques are extracellular deposits of amyloid beta in the grey matter of the brain and were considered together with neurofibrillary tangles as characteristic features of $\mathrm{AD}$. The majority of the histopathological changes of $\mathrm{AD}$ rats in the present study agreed with previous studies ${ }^{35-37)}$. These severe changes in the brain clarified that treatment with $\mathrm{Al}$ lactate with simultaneous consumption of the diet that enhanced CVD risk succeeded to induce $\mathrm{AD}$ model in the present study.

Fish oil, primrose oil and their mixture showed variable suppressions in the progression of $\mathrm{AD}$ like model in rats as could be observed in the present study through anti-inflammatory, antioxidant, BChE inhibiting effect and elevation of $\mathrm{Mg}$ level. The concomitant improvement of lipid profile and T-C/HDL-C by the tested oils also plays an important role in inhibiting the progression of AD. Fatty acid analysis of the studied oil demonstrated the presence of bioactive fatty acids. It was reported that evening primrose oil contained gamma-linolenic (9.24\%), linoleic (73.88\%), oleic $(6.93 \%)$, palmitic $(6.31 \%)$, stearic $(1.88 \%)$, vaccenic $(0.81 \%)$, eicosenoic $(0.55 \%)$, eicosanoic $(0.31 \%)$ and behenic $(0.1 \%)^{38)}$. Two types of omega- 6 fatty acids were reported to present in EPO, gamma-linolenic as 8-14\% and linoleic acid (60-80\%) as essential fatty acids ${ }^{39)}$. Fatty acid analysis of primrose oil in the present study showed similar results to the aforementioned researches concerning the level of gamma-linolenic, linoleic acid and palmitic while oleic and steric demonstrated slightly higher level in the current study. Also vaccenic, eicosenoic, eicosanoic and behenic were not identified in the present study with the presence of traces from arashidic that was not observed in the previous research. This could be ascribed to difference in cultivated areas and other environmental conditions. The fatty acids present in fish oil used in the present research were analyzed in a previous work ${ }^{13)}$ and was shown to contain EPA as $22.768 \%$, DHA as $13.574 \%$, oleic as $12.771 \%$, linoleic as $2.379 \%$, $\alpha$ - linolenic as $3.368 \%$, palmitoleic as $9.349 \%$ and total saturated fatty acids as $31.169 \%$.

Gamma-linolenic in primrose oil was reported as precursor of anti-inflammatory eicosanoids ${ }^{40}$..$\Delta^{6}$ Desaturase is present in very little quantity in rats and human. Gammalinolenic acid is a product of $\Delta^{6}$ desaturase in the body; therefore, supplement of gamma-linolenic acid can bypass $\Delta^{6}$ desaturase step. So, gamma-linolenic acid is elongated to dihomo gamma-linolenic acid which is then converted to arachidonic acid by $\Delta^{5}$ desaturase. Key inflammatory cells lack $\Delta^{5}$ desaturase which results in accumulation of dihomo gamma-linolenic acid relative to arachidonic acid. Dihomo gamma-linolenic acid can then combine to 5-lipoxygenase and compete to arachidonic acid leading to inhibition of leukotrienes. Dihomo gamma-linolenic acid released from polymorphonuclear granulocytes can be metabolized to 15-hydroxytrienoic acid (15-lipoxygenase product); therefore leukotriene B4 biosynthesis was inhibited by either dihomo gamma-linolenic acid or 15-hydroxytrienoic acid. On the other hand, dihomo gamma-linolenic acid could be metabolized by cyclooxygenase to 1-series prostaglandins. These actions denote the anti-inflammatory activity of gamma-linolenic acid. Thus, in addition to direct inhibition of critical enzymes that regulate lipid mediator production, dihomo gamma-linolenic acid can be converted by lipooxygenases and cyclooxygenases to products that can serve as modulators of the conversion of arachidonic acid to leukotriene and prostaglandins. It is worth to mention that due to the very little activity of $\Delta^{6}$ desaturase in human and rat, linoleic acid (n-6 fatty acid) cannot be converted to gammalinolenic acid in the body by a comparable amount that could be supplemented from primrose oil and therefore cannot undergo the abovementioned passway.

The inflammatory mediator interleukin $1 \mathrm{~B}$ and 6 and tumor necrosis factor-alpha were inhibited by gamma-linolenic $^{12)}$. Also improving lipid profile in the present study by gamma-linolenic acid agreed with previous studies that showed reduction in serum triglycerides and total cholesterol in hyperlipidemic mice and rats ${ }^{13,41}$ and this may potentiate the efficiency of primrose in reducing the progression of $\mathrm{AD}$.

A diet high in n-3 fatty acids was associated with lower risk of $\mathrm{AD}^{42}$. A diet rich in DHA reduced overall plaque 
burden in mice brain ${ }^{43)}$. DHA and EPA supplementation to $\mathrm{AD}$ patients produced reduction in the inflammatory markers IL1B and IL6 thereby reduce the dysfunction of neurons ${ }^{44)}$. However there is a conflicting results concerning the role of n-3 fatty acids towards cognitive function ${ }^{45-47}$. Cerebral microinfarction and functional deficit which have significant effect in the development of $\mathrm{AD}$ were reduced by supplementation of n-3 polyunsaturated fatty acids ${ }^{48)}$. Lipid peroxidation and reactive oxygen species were reduced while antioxidant enzymes including catalase were increased in rat brain microvascular endothelial cells when incubated with $\mathrm{n}-3$ fatty acids ${ }^{49)}$ pointing to their antioxidant and neuroprotective effect. Fish oil attenuated neuroinflammatory gene expression in mouse model of $\mathrm{AD}^{50)}$. The beneficial effect of $\mathrm{n}-3$ fatty acids in $\mathrm{AD}$ is attributed to antioxidant, anti-inflammatory, antiapoptotic and neurotrophic properties ${ }^{51)}$. Reductions of cytokines and monocytic chemotactic protein 1 by fish oil reflect its anti-inflammatory effect and these are accomplished by inhibiting $\mathrm{NF}-\kappa \mathrm{B}$ as could be seen in the present study. Fish oil also suppresses nitric oxide synthase and cyclooxygenase activities. The antiapoptotic activity of EPA and DHA is mediated through reducing caspase 3 . They enhance expression of superoxide dismutase thereby elucidate the antioxidant activity. Nerve growth factor level is enhanced by DHA and $\mathrm{EPA}^{51}$. Cardiovascular protective effect of fish oil as could be noticed from the current study and previous work ${ }^{13)}$ might participate in reducing $\mathrm{AD}$ progression in the present work.

Both fish oil and primrose oil were shown previously to possess anti-inflammatory activity in rheumatoid arthritis patient ${ }^{52}$. Menhaden oil (rich in EPA and DHA) was shown to be more efficient than evening primrose oil in improving vascular and neural complications of diabetic $\operatorname{rats}^{53)}$. The improved body weight gain and brain weight of $\mathrm{AD}$ rats after administration of the tested oils might also reflect improvement of $\mathrm{AD}$ in the present study. DHA and EPA were reported to enhance body weight gain in patients with $\mathrm{AD}$ that suffer from body weight reduction ${ }^{54)}$. The present work showed body weight gain of $\mathrm{AD}$ treated by the oil mixture to match that of the CN. Mixture from fish oil and primrose oil as in the present study might demonstrate the biological activity as a result of synergistic effect of EPA, DHA and gamma linolenic acids collectively thereby showed superiority in reducing ESR, brain MDA, plasma activity of $\mathrm{BChE}$ and brain histopathological changes along with elevating plasma $\mathrm{Mg}$ compared to the individual oils. The presence of oleic acid and linoleic acid in the three tested oils might also participate in their biological activity. Linoleic acid was reported to protect against the proinflammatory effect of lipid ${ }^{55)}$ while oleic possessed cardioprotective effect ${ }^{56}$ which might alleviate the risk of cardiovascular diseases with subsequent reduction of $\mathrm{AD}$ progression.

\section{Conclusion}

Fish oil, primrose oil and primrose/fish oil mixture reduced the progression of Alzheimer's like disease in rat model. Primrose/fish oil mixture was superior in reducing ESR, brain MDA, plasma activity of BChE and brain histopathological changes along with elevating plasma Mg. Fish oil was the most efficient in improving plasma T-C, LDL-C and T-C/HDL-C. Primrose/fish oil mixture and fish oil were more promising in improving plasma HDL-C than primrose. Primrose/fish oil mixture and primrose oil were more efficient in elevating brain CAT compared to fish oil. Other parameters represented by plasma TG, body weight gain and brain GSH, NO, myeloperoxidase, NF- $\mathrm{kB}$ and brain weight were more or less equally improved by the three tested oils. These oils might be capable to afford health benefits towards AD patients and cardiovascular disorders.

\section{Acknowledgments}

The research was carried out in National Research Centre, Egypt. The research did not receive any specific grant from funding agencies in the public, commercial, or not-for-profit sectors and was implemented on the expense of the authors.

\section{Conflict of Interest Statement}

The authors declare that they have no conflict of interest.

\section{References}

1) Zatta, P. In vivo and in vitro effects of aluminum on the activity of mouse brain acetyl cholinesterase. Brain. Res. Bull. 59, 41-45 (2002).

2) Kawahara, M. Effects of aluminum on the nervous system and its possible link with neurodegenerative diseases. J. Alzheimers Dis. 8, 171-182 (2005).

3) Rapaka, D.; Bitra, V.R.; Vishala, T.C.; Akula, A. Vitis vinifera acts as anti-Alzheimer's agent by modulating biochemical parameters implicated in cognition and memory. J. Ayurveda Integr. Med. 10, 241-247 (2019).

4) Gulya, K.; Rakonczay, Z.; Kasa, P. Cholinotoxic effects of aluminum in rat brain. J. Neurochem. 54, 10201026 (1990).

5) Al-Okbi, S.Y.; Mohamed, D.A.; Abdel Fatah, M.; Aal, K.A.; Mohammed, S.E. Evaluation of plant food extracts in experimental model of Alzheimer's like disease induced by aluminum lactate in rats. J. Appl. Pharm. Sci. 7(7), 70-76(2017). 
6) Green, P.S.; Mendez, A.J.; Jacob, J.S.; Crowley, J.R.; Growdon, W.; Hyman, B.T.; Heinecke, J.W. Neuronal expression of myeloperoxidase is increased in Alzheimer's disease. J. Neurochem. 90, 724-733(2004).

7) Jones, S.V.; Kounatidis, I. Nuclear factor-kappa B and Alzheimer disease, unifying genetic and environmental risk factors from cell to humans. Front. Immunol. 8, 1805 (2017).

8) Madhavadas, S.; Kutty, B.M.; Subramanian, S. Amyloid beta lowering and cognition enhancing effects of ghrelin receptor analog [D-Lys (3) ] GHRP- 6 in rat model of obesity. Indian J. Biochem. Biophys. 51, 257-262 (2014).

9) Yaseen, A.A.; Al-Okbi, S.Y.; Hussein, A.M.S.; Mohamed, D.A.; Mohammad, A.A.; Fouda, A.A.; Mehaya, F.M. Potential protection from Alzheimer's disease by wheat germ and rice bran nano-form in rat model. J. Appl. Pharm. Sci. 9(S1), 067-076(2019).

10) Swanson, D.; Block, R.; Mousa, S.A. Omega-3 fatty acids EPA and DHA: Health benefits throughout life. Adv. Nutr. 3, 1-7(2012).

11) Yan, L.; Xie, Y.; Satyanarayanan, S.K.; Zeng, H.; Liu, Q.; Huang, M.; Ma, Y.; Wan, J.B.; Yao, X; Su, KP; Su, H. Omega-3 polyunsaturated fatty acids promote brainto-blood clearance of $\beta$-Amyloid in a mouse model with Alzheimer's disease. Brain. Behav. Immun. 85, 35-45 (2020).

12) Timoszuk, M.; Bielawska, K.; Skrzydlewska, E. Evening primrose (Oenothera biennis) biological activity dependent on chemical composition. Antioxidants 7 (8), 108 (2018).

13) Al-Okbi, S.Y.; El-qousy, S.M.; El-Ghlban, S.; Moawad, H.F. Role of borage seed oil and fish oil with or without turmeric and alpha- tocopherol in prevention of cardiovascular disease and fatty liver in rats. J. Oleo Sci. 67, 1551-1562 (2018).

14）Indarti, E.; Majid, M.I.A.; Hashim, R.; Chong, A. Direct FAME synthesis for rapid total lipid analysis from fish oil and cod liver oil. J. Food Compost. Anal. 18, 161170 (2005).

15) Al-Okbi, S.Y.; Abdel-Razek, A.G.; Mohammed, S.E.; Ottai, M.E. Roselle seed as a potential new source of healthy edible oil. J. Biol. Sci. 17, 267-277 (2017).

16) Al-Okbi, S.Y.; Mohamed, D.A.; Kandil, E.; Ahmed, E.K.; Mohammed, S.E. Functional ingredients and cardiovascular protective effect of pumpkin seed oils. Grasas y Aceites 65 (1), e007 (2014).

17) Matsumoto, T.; Sato, A.; Suenaga, H.; Kobayashi, T.; Kamata, K. Modulations of shear stress-induced contractile responses and agonist-induced vasodilation in hypercholesterolemic rats. Atherosclerosis 175, 31-38 (2004).

18) Westergren A. Studies of the suspension stability of the blood in pulmonary tuberculosis. Acta Medica
Scand. 54, 247-282(1921).

19) Burstein, M.; Scholnick, H.R.; Morfin, R. Rapid method for the isolation of lipoproteins from human serum by precipitation with polyanions. J. Lipid Res. 11, 583$595(1970)$.

20) Megraw, R.; Dunn, D.; Biggs, H. Manual and continuous flow colorimetry of triacylglycerols by a fully enzymatic method. Clin. Chem. 25, 273-278(1979).

21) Richmond, W. Preparation and properties of a cholesterol oxidase from Nocardia sp. and its application to the enzymatic assay of total cholesterol in serum. Clin. Chem. 19, 1350-1356 (1973).

22) Friedewald, W.T.; Levy, R.I.; Fredrickson, D.S. Estimation of the concentration of low-density lipoprotein cholesterol in plasma, without use of the preparative ultracentrifuge. Clin. Chem. 18, 499-502(1972).

23) Knedel, M.; Bo "ttger, R. A kinetic method for determination of the activity of pseudocholinesterase (acylcholine acyl-hydrolase 3.1.1.8.). Wein. Klin. Wochenschr. 45(6), 325-327 (1967).

24) Farrell, E.C. Magnesium. in Clinical Chemistry (Kaplan, L.A. et al. eds.), The CV Mosby Co., St Louis, Toronto, Princeton, pp. 1065-1070 (1984).

25) Montgomery, H.A.C.; Dymock, J.F. The determination of nitrite in water. Analyst 86, 414-416 (1961).

26) Satoh K. Serum lipid peroxide in cerebrovascular disorders determined by a new colorimetric method. Clin. Chim. Acta 90, 37-43 (1978).

27) Beutler, E.; Duron, O.; Kelly, M.B. Improved method for the determination of blood glutathione. J. Lab. Clin. Med. 61, 882-888(1963).

28) Aebi, H. Catalase in vitro. Methods Enzymol. 105, 121-126 (1984).

29) Sanderson, T.; Wild, G.; Cull, A.M.; Marston, J.; Zardin, G. Immunohistochemical and immunofluorescent techniques. in Bancroft's Theory and Practice of Histological Techniques (Suvarna, S.K.; Layton, C.; Bancroft, J.D. eds.) Vol. 8, Elsevier, pp. 337-394 (2019).

30) Bancroft, J.D.; Layton C. The hematoxylins and eosin. in Bancroft's Theory and Practice of Histological Techniques (Suvarna, S.K.; Layton, C.; Bancroft, J.D. eds.) Vol. 8, Elsevier, pp. 126-138(2019).

31) Prema, A.; Justin Thenmozhi, A.; Manivasagam, T.; Mohamed Essa, M.; Guillemin, G.J. Fenugreek seed powder attenuated aluminum chloride induced tau pathology, oxidative Stress, and inflammation in a rat model of Alzheimer's disease. J. Alzheimers Dis. 60 (S1), S209-S220 (2017).

32) Mushtaq, G.; Greig, N.H.; Khan, J.A.; Kamal, M.A. Status of acetylcholinesterase and butyrylcholinesterase in Alzheimer's disease and type 2 diabetes mellitus. CNS Neurol. Disord. Drug Targets 13, 1432-1439 (2014). 
33) Slutsky, I.; Abumaria, N.; Wu, L.J.; Huang, C.; Zhang, L.; Li, B.; Zhao, X.; Govindarajan, A.; Zhao, M.G.; Zhuo, M.; Tonegawa, S.; Liu, G. Enhancement of learning and memory by elevating brain magnesium. Neuron 65, 165-177 (2010).

34) Chui, D.; Chen, Z.; Yu, J.; Zhang, H.; Wang, W.; Song, Y.; Yang, H.; Liu, Y. Magnesuim in Alzheimer's disease. in Magnesuim in the Central Nervous System (Vink, R.; Nechifor, M. eds.) Adelaide, University of Adelaide Press, pp. 239-250 (2011).

35) Kandimalla, R.; Vallamkondu, J.; Corgiat, E.B.; Gill, K.D. Understanding aspects of aluminum exposure in Alzheimer's disease development. Brain Pathol. 26, 139-154 (2016).

36) Castorina, A.; Tiralongo, A.; Giunta, S.; Luisa Carnazza, M.; Scapagnini, G. Early effects of aluminum chloride on beta-secretase mRNA expression in a neuronal model of b-amyloid toxicity. Cell Biol. Toxicol. 26, 367-377 (2010).

37) Olajide, O.J.; Yawson, E.O.; Gbadamosi, I.T.; Arogundade, T.T.; Lambe, E.; Obasi, K.; Lawal, I.T.; Ibrahim, A.; Ogunrinola, K.Y. Ascorbic acid ameliorates behavioural deficits and neuropathological alterations in rat model of Alzheimer's disease. Environ. Toxicol. Pharmacol. 50, 200-211(2017).

38) Montserrat-de la Paz, S.; Fernandez-Arche, M.A.; Angel-Martin, M.; Garcia-Gimenez, M.D. Phytochemical characterization of potential nutraceutical ingredients from evening primrose oil(Oenothera biennis L.). Phytochem. Lett. 8, 158-162(2014).

39) Barrett, M. The handbook of clinically tested herbal remedies. The Haworth Herbal Press, Birmingham (NY) (2004).

40) Chilton, F.H.; Rudel, L.L.; Parks J.S.; Arm, J.P.; Seeds, M.C. Mechanisms by which botanical lipids affect inflammatory disorders. Am. J. Clin. Nutr. 87, 498S503S (2008).

41) Ide, T.; Origuchi, I. Physiological effects of an oil rich in $\gamma$-linolenic acid on hepatic fatty acid oxidation and serum lipid levels in genetically hyperlipidemic mice. J. Clin. Biochem. Nutr. 64, 148-157(2019).

42) Gu, Y.; Nieves, J.W.; Stern, Y.; Luchsinger, J.A.; Scarmeas, N. Food combination and Alzheimer disease risk: A protective diet. Arch. Neurol. 67, 699-706 (2010).

43) Lim, G.P.; Calon, F.; Morihara, T.; Yang, F.; Teter, B.; Ubeda, O.; Salem, N.Jr.; Frautschy, S.A.; Cole, G.M. A diet enriched with the omega-3 fatty acid docosahexaenoic acid reduces amyloid burden in an aged $\mathrm{Al}$ zheimer mouse model. J. Neurosci. 25, 3032-3040 (2005).

44) Vedin, I.; Cederholm, T.; Freund Levi, Y.; Basun, H.; Garlind, A.; Faxen Irving, G.; Jonhagen, M.E.; Vessby, B.; Wahlund, L.O.; Palmblad, J. Effects of docosa- hexaenoic acid-rich n-3 fatty acid supplementation on cytokine release from blood mononuclear leukocytes: the OmegAD study. Am. J. Clin. Nutr. 87, 1616-1622 (2008).

45) Freund-Levi, Y.; Eriksdotter-Jonhagen, M.; Cederholm, T.; Basun, H.; FaxenIrving, G.; Garlind, A.; Vedin, I.; Vessby, B.; Wahlund, L.O.; Palmblad, J. Omega-3 fatty acid treatment in 174 patients with mild to moderate Alzheimer disease: Omeg AD study: a randomized double-blind trial. Arch. Neurol. 63, 1402-1408 (2006).

46) Quinn, J.F.; Raman, R.; Thomas, R.G.; Yurko-Mauro, K.; Nelson, E.B.; Van Dyck, C.; Galvin, J.E.; Emond, J.; Jack, C.R.Jr.; Weiner, M. et al. Docosahexaenoic acid supplementation and cognitive decline in Alzheimer disease: a randomized trial. JAMA 304, 1903-1911 (2010).

47) Vela, S.; Sainz, N.; Moreno-Aliaga, M.J.; Solas, M.; Ramirez, M.J. DHA selectively protects SAMP-8-associated cognitive deficits through inhibition of JNK. Mol. Neurobiol. 56, 1618-1627 (2019).

48) Luoa, C.; Rena, H.; Yaoc, X.; Shia, Z.; Liang, F.; Kangd, J.X.; Wan, J.; Pei, Z.; Su, K.; Sua, H. Enriched brain omega-3 polyunsaturated fatty acids confer neuroprotection against microinfarction. EBioMedicine 32, 50-61 (2018).

49) Wang, L.; Fan, H.; He, J.; Wang, L.; Tian, Z.; Wang, C. Protective effects of omega-3 fatty acids against Alzheimer's disease in rat brain endothelial cells. Brain and Behavior 8, e01037 (2018).

50) Hopperton, K.E.; Trépanier, M.O.; James, N.C.E.; Chouinard-Watkins, R.; Bazinet, R.P. Fish oil feeding attenuates neuroinflammatory gene expression without concomitant changes in brain eicosanoids and docosanoids in a mouse model of Alzheimer's disease. Brain Behav. Immun. 69, 74-90 (2018).

51) Ajith, T.A. A recent update on the effects of omega-3 fatty acids in Alzheimer's disease. Curr. Clin. Pharmacol. 13, 252-260 (2018).

52) Al-Okbi, S.Y.; Ammar, N.M; Soroor, Kh.A.; Mohammed, D.A. Impact of natural oils supplements on disease activity and antioxidant state of Egyptian patients with rheumatiod arthritis. Med. J. Islamic Acad. Sci. 13 (4), 161-171 (2000).

53) Coppey L.; Davidson, E.; Shevalye, H. ; Obrosov, A.; Yorek, M. Effect of early and late interventions with dietary oils on vascular and neural complications in a type 2 diabetic rat model. J. Diabetes Res. 2019, 5020465 (2019).

54) Irving, G.F.; Freund-Levi, Y.; Eriksdotter-Jonhagen, M.; Basun, H.; Brismar, K.; Hjorth, E.; Palmblad, J.; Vessby, B.; Vedin, I.; Wahlund, L.O.; et al. Omega-3 fatty acid supplementation effects on weight and appetite in patients with Alzheimer's disease: the omega-3 Alzheim- 
S. Y. Al-Okbi, S. E Mohammed, E. S.K. Al-Siedy et al.

er's disease study. J. Am. Geriatr. Soc. 57, 11-17 (2009).

55) Maruyama, H.; Takahashi, M.; Sekimoto, T.; Shimada, T.; Yokosuka, O. Linoleate appears to protect against palmitate-induced inflammation in Huh7 cells. Lipids
Health Dis. 13, 78(2014).

56) Christon, R.A. Mechanisms of action of dietary fatty acids in regulating the activation of vascular endothelial cells during atherogenesis. Nutr. Rev. 61, 272-279 (2003). 